\title{
TRABALHO E SUBJETIVIDADE: UMA PERSPECTIVA DE ANÁLISE COMPORTAMENTAL WORK AND SUBJECTIVITY: A BEHAVIOR-ANALYTIC ACCOUNT
}

\author{
Rosângela Araújo Darwich ${ }^{1}$ \\ Raphael Samir do Nascimento Monteiro²
}

\section{RESUMO}

Este estudo de campo objetivou relacionar a subjetividade de trabalhadores às experiências deles no trabalho, na perspectiva da Análise do Comportamento. Para tanto, comparou-se a percepção de trabalhadores de diferentes cargos de uma dada organização no tocante a reforçadores por eles identificados no ambiente de trabalho. A noção de reforçamento deriva da relação estabelecida entre ações e consequências por elas geradas, fundamental para a compreensão das interações que o indivíduo estabelece com o seu meio, com outros indivíduos e consigo próprio. Partindo dessa noção, foi realizada análise quantitativa descritiva a partir de dados coletados por meio de entrevista semiestruturada com vinte participantes, os quais que foram divididos em dois grupos, Grupo Tático e Grupo Operacional, conforme o nível hierárquico por eles ocupado. Os resultados demonstraram que os participantes de ambos os grupos identificaram de maneira semelhante a presença de reforçadores em seus ambientes de trabalho, implicando adequação a seus respectivos cargos. Argumenta-se que a análise de contingências permite a compreensão de relações entre características subjetivas dos trabalhadores e o cargo assumido, favorecendo o reconhecimento de variáveis relacionadas à satisfação pessoal no contexto profissional.

Palavras-chave: Subjetividade. Reforçadores. Análise Do Comportamento.

1 Doutora em Psicologia: Teoria e Pesquisa do Comportamento. Universidade da Amazônia. E-mail: rosangeladarwich@ yahoo.com.br

2 Bacharel em Psicologia. E-mail: raphael-samir@hotmail.com 


\section{ABSTRACT}

This field study relates employees' subjectivity to their experiences in the work environment. To this purpose, we adopt the perspective of behavior analysis and compare how employees from different positions in a given organization perceive reinforcers in their work environment. The notion of reinforcement relates an individual's actions to the consequences generated by these same actions and is thus fundamental to understand a person's interactions with his/her environment, with other individuals and with himself/herself. With this notion in mind, a quantitative descriptive analysis was performed on data collected through a semi-structured interview with twenty participants, who were divided into two groups, Tactical Group and Operational Group, according to the hierarchical level they occupied in the organization. The results showed that the participants of both groups similarly identified the presence of reinforcers in their work environments, implying adequacy to their respective positions in the organization. It is argued that contingency analysis allows not only the understanding of relationships between employees' subjective characteristics and the position they assume, but also favors the recognition of factors related to personal satisfaction in the professional context.

Keywords: Subjectivity. Reinforcers. Behavior Analysis.

\section{INTRODUÇÃO}

Com o advento da tecnologia, as organizações passaram por enormes mudanças, sendo exigido delas capacidade de se renovar para se adequar às novas demandas. O período vivenciado atualmente pelas organizações é chamado de era da informação, que iniciou na década de 1990, tendo, como características principais, mudanças rápidas, imprevistas e inesperadas. Com isso, os trabalhadores passaram a se constituir enquanto parceiros de mudanças (BORGES, 2000; CASTELLS, 2002; RADOS et al, 2016).

Se os indivíduos são os principais ativos da organização, a área de gestão de pessoas é responsável pela realização dos objetivos organizacionais. Uma das principais ações é o processo de manter pessoas em suas funções, criando condições ambientais e psicológicas satisfatórias para tanto. De acordo com Zanelli (2004), recentemente passou-se a prestar atenção nas relações estabelecidas no contexto imediato de trabalho, enfatizando-se interações entre características do trabalhador, natureza do trabalho, estrutura organizacional e ambiente externo. O tema competência vem sendo analisado também ao nível dos países, para além das instâncias de compreensão do indivíduo e das organizações (FLEURY; FLEURY, 2001).

O último relatório anual de absenteísmo da Alemanha detalha relações entre saúde e vivência de significado no trabalho. É destacado o valor de experiências subjetivas no combate ao absenteísmo em uma perspectiva ampla, que inclui variáveis individuais, sociais e do próprio ambiente de trabalho. Uma questão central: como as organizações podem ajudar seus trabalhadores a vivenciar as atividades que desenvolvem como sendo significativas, com propósitos que os aproximem de si mesmos e do contexto de trabalho? Em outros termos: como reunir trabalho, saúde e qualidade de vida? (BADURA et al, 2018). 
No Brasil, uma investigação quantitativa da produção científica reunida em periódicos científicos nacionais entre 2005 e 2015 acerca do tema "qualidade de vida no trabalho" destaca o seguinte pressuposto: existe uma relação diretamente proporcional entre satisfação ou envolvimento nas tarefas desenvolvidas e produtividade no trabalho (PICOLLI; CASAGRANDE, 2017).

Absenteísmo e produtividade são fatores de reconhecimento e quantificação mais simples do que aspectos subjetivos, como satisfação, significado e propósito. A compreensão de relações entre os dois tipos de variáveis pode ser favorecida pelo estabelecimento de pontes entre contexto, ação, pensamento e emoção, aproximando o meio físico e social à subjetividade dos que dele participam. Para tanto, este estudo lança mão de princípios básicos da Análise do Comportamento, destacando compromissos de interdisciplinaridade entre ciência psicológica e ciência administrativa.

Na perspectiva da Análise do Comportamento, uma ferramenta útil para a compreensão de interações humanas é baseada no reconhecimento de relações de contingências operantes, caracterizadas de acordo com a consequência gerada por uma ação realizada em um dado contexto. Neste sentido, o reforçamento está relacionado ao aumento da probabilidade de determinadas ações voltarem a acontecer, e pode ser dividido em positivo e negativo. O reforçamento positivo corresponde ao acréscimo de estímulo reforçador após a atitude tomada, seja tal estímulo dinheiro, elogio ou mesmo um sorriso ou qualquer outra expressão de aprovação ou reconhecimento. Quando os atos de um indivíduo o aproximam de seus desejos e ideais, as consequências reforçadoras sinalizam que a direção foi correta ou coerente, ainda que esse efeito não seja claramente reconhecido para além das emoções que o acompanham. Em complemento à noção de reforçamento positivo, o reforçamento negativo se faz presente quando a ação de fuga ou de esquiva de punições presentes ou imaginadas é acompanhada pela retirada ou pela não apresentação de um estímulo punitivo. Em tais casos, perdas monetárias ou de apreço, por exemplo, são evitadas, e o sentimento correspondente costuma ser de alívio (CATANIA, 1998; MOREIRA; MEDEIROS, 2007).

Fugas e esquivas estão diretamente relacionadas aos riscos previstos quando se vive em contextos punitivos. A punição diminui a probabilidade de determinadas ações voltarem a acontecer por meio do acréscimo de um estímulo punitivo, como repreensões e castigos físicos, ou da retirada de um estímulo reforçador, como em situações em que se perde algum tipo de abono ou gratificação, principalmente quando as regras adotadas são inflexíveis e de difícil compreensão por quem é submetido a elas. Aqui, o preço da obediência é o medo e a ansiedade, a insegurança diante de novas oportunidades e o contato constante com catástrofes imaginadas. Aprender a lidar com punições e com ameaças de castigo se tornou um desafio social, mesmo porque esquivas de prováveis punições tendem mais a manter vivos os problemas do que a solucioná-los. Um ambiente de trabalho punitivo, por exemplo, é um desafio constante ao equilíbrio daqueles que dele participam (SIDMAN, 1989).

No caso de ocorrência de reforçamento positivo, algumas especificidades precisam ser destacadas. O estímulo reforçador, que acompanha a ação, é considerado como contingente ou intrínseco quando o resultado gerado é o próprio comportamento, como quando se executa uma tarefa por si só prazerosa. No caso dos reforçadores não contingentes ou extrínsecos, a satisfação não corresponde à ação, mas acompanha a consequência por ela gerada, como quando uma atividade desempenhada é recompensada por dinheiro (CAMPOS, 2009; CATANIA, 1998). 
Dentre os reforçadores extrínsecos destacam-se os reforçadores generalizados, cuja eficácia é verificada sob variados estados de privação e, portanto, em contextos variados. É o caso da atenção, da aprovação e de estímulos simbólicos, como o próprio dinheiro. A atenção e a aprovação, além disso, correspondem a um tipo especial de reforçador generalizado, identificado como reforçador social, já que advém da mediação por outro indivíduo (SKINNER, 2003).

Vale repetir que o contato com a consequência gerada pela ação, ou resposta operante, gera alterações fisiológicas características da experiência de emoções (DARWICH; TOURINHO, 2005). Neste sentido, considera-se que o contato com diferentes tipos de reforçadores positivos seja responsável por uma maior qualidade de vida e, no ambiente de trabalho, pela ligação íntima entre obrigação e prazer. Por outro lado, o reforçamento negativo estaria relacionado a uma ênfase maior em atividades realizadas apenas por obrigação e, assim, desvinculadas de satisfação pessoal. Compreender a percepção que trabalhadores têm sobre os estímulos reforçadores que a organização disponibiliza é, portanto, fundamental para qualquer prática da área de gestão de pessoas na empresa, como investigações acerca de relações de trabalho, satisfação profissional e mesmo rotatividade de pessoal.

Em linhas gerais, este estudo objetivou relacionar experiências no trabalho a fatores subjetivos de trabalhadores com funções diferenciadas. Para tanto, com base em princípios da Análise do Comportamento, respostas referentes à percepção de trabalhadores de cargos tático e operacional foram comparadas no tocante a reforçadores identificados no ambiente de trabalho.

\section{METODOLOGIA}

Este estudo de campo lançou mão de método quantitativo descritivo de análise de dados, os quais foram coletados por meio de uma entrevista semiestruturada, com perguntas abertas e fechadas, que investigou a presença de diferentes reforçadores, intrínsecos extrínsecos, generalizados e sociais, na experiência de trabalho dos participantes, relacionando o cotidiano presente a expectativas de futuro.

A coleta de dados foi realizada em uma empresa paraense de porte médio, do setor de materiais de construção civil, fundada em 2006 e com lojas situadas em bairros da periferia de Belém. Os vinte participantes foram divididos em dois grupos: grupo de trabalhadores com cargo de nível tático (Grupo Tático) e operacional (Grupo Operacional). Tal divisão foi realizada a fim de possibilitar comparações entre efeitos do contato com atividades mais complexas e mais bem remuneradas, no caso de participantes do Grupo Tático, e da realização de tarefas mais diretamente ligadas à obediência direta de ordens e com menor reconhecimento social, no caso de participantes do Grupo Operacional.

Compuseram o Grupo Tático quatro participantes do sexo feminino e seis, do sexo masculino. O tempo de permanência no cargo variou de sete meses (10\% dos entrevistados) a dois anos (30\% dos entrevistados), com média de 1,4 ano. O Grupo Operacional foi composto por uma participante do sexo feminino e nove, do sexo masculino. O tempo de permanência no cargo variou de oito meses (30\% dos entrevistados) a quinze anos (10\% dos entrevistados), com média aproximada de 2,6 anos. Na amostra, portanto, os trabalhadores do Grupo Operacional apresentaram um tempo maior na organização, com uma diferença média de mais de um ano no cargo. 
Detalhamentos acerca dos cargos ocupados pelos participantes dos dois grupos são apresentados no Gráfico 1.

Gráfico 1. Cargos ocupados pelos participantes
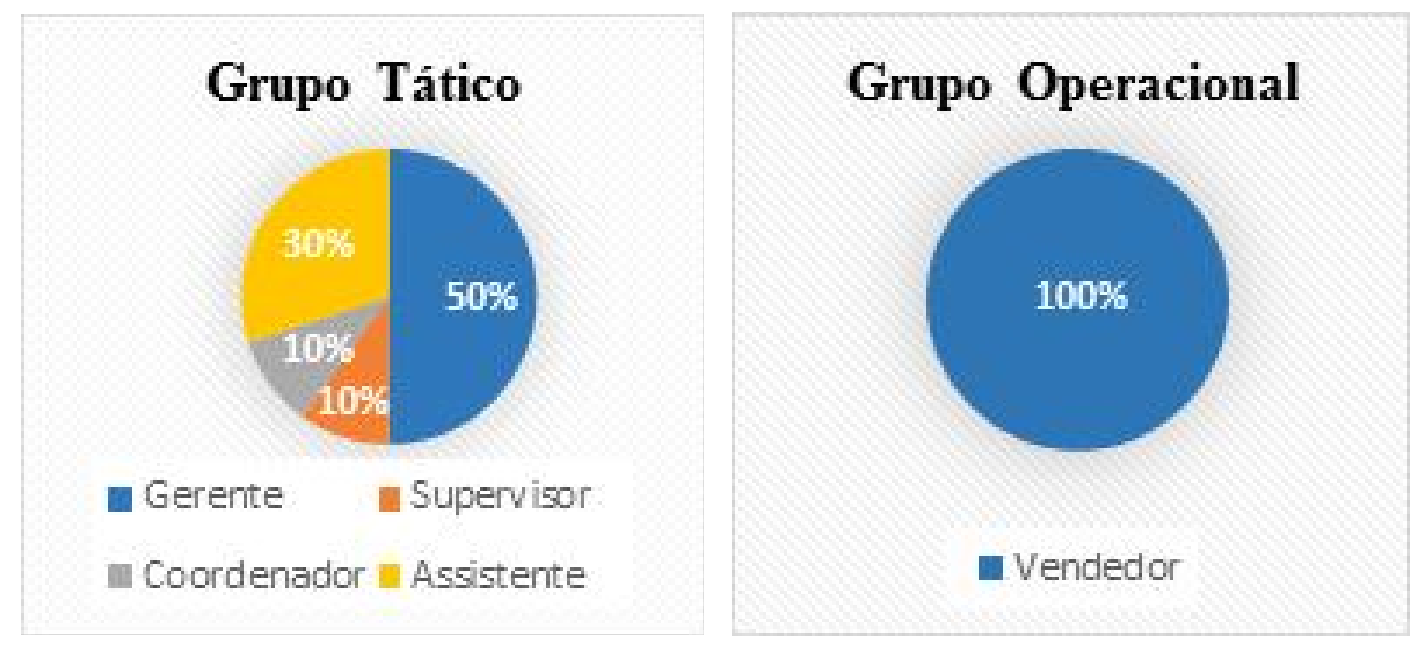

Fonte: Elaboração própria

Todos os participantes do Grupo Operacional ocupavam o cargo de vendedor, enquanto quatro diferentes cargos foram ocupados pelo Grupo Tático: gerente (50\%), supervisor, coordenador e assistente. De acordo com Freitas e Kladis (1995), cargos táticos têm em comum tarefas relacionadas com controle administrativo e decisões sobre operações de controle, e formulação de regras de decisão. Cargos operacionais, por outro lado, envolvem a execução de atividades referentes às decisões estabelecidas nos níveis tático e estratégico.

Paracompreender os reforçadores com os quais os participantes dos dois grupos costumeiramente entram em contato em seus respectivos locais de trabalho, primeiramente lhes foi repassado o Termo de Consentimento Livre e Esclarecido (TCLE), garantindo a ética na pesquisa e o resguardo dos seus direitos, como o anonimato e a preservação do bem-estar ${ }^{1}$. Entrevistas semiestruturadas, com oito perguntas, foram realizadas na organização em que os participantes trabalhavam, ao longo de três dias, em sala disponibilizada pela própria organização.

Em consideração ao número de participantes, as respostas apresentadas por eles são descritas na seção seguinte em gráficos de pizza, aos pares, de modo a facilitar a comparação entre os dois grupos e, assim, de maneira geral, a discriminação de reforçadores específicos a cada um tipo de cargo.

\section{RESULTADOS E DISCUSSÃO: TRABALHO E SUBJETIVIDADE}

A entrevista semiestruturada foi construída de modo a possibilitar o acesso à percepção dos participantes de forma ampla, embora partindo de situações de trabalho. Compreende-se que a subjetividade deriva de trocas sociais estabelecidas no presente e ao longo da vida, assim como o modo como se lida com diferentes áreas e com os impactos daí resultantes (SKINNER, 2003).

A primeira pergunta, "em seu trabalho você tem a oportunidade de fazer todos os dias aquilo que você sabe fazer de melhor?", está relacionada ao contato com reforço intrínseco no ambiente trabalho. Para Bajoit e Franssen (1997), a maior parte do discurso do trabalhador sobre 
sua vida profissional remete ao processo de seu trabalho, de modo que a identidade profissional está ligada à prática rotineira das suas atividades na organização. Com isso, a presença de reforçadores intrínsecos na prática diária dos participantes teoricamente acrescentaria sentido e motivação ao trabalho realizado.

Gráfico 2. Reforço intrínseco
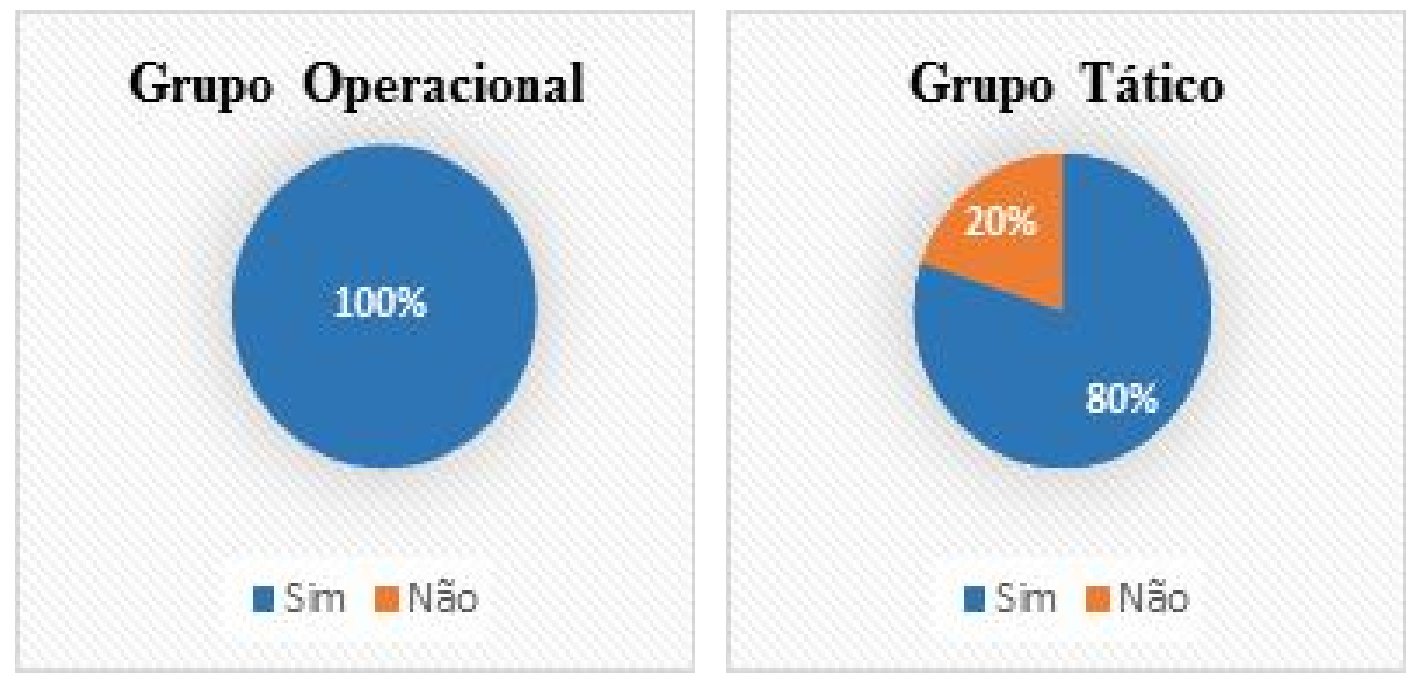

Fonte: Elaboração própria

Todos os participantes do Grupo Operacional e 80\% daqueles do Grupo Tático responderam de forma positiva à primeira pergunta, reconhecendo que têm oportunidade, no trabalho, de fazer aquilo que sabem fazer de melhor.

Segundo Evans (1996), trabalhadores de nível tático são responsáveis por projetos de desenvolvimento e mudanças internas e externas na organização, e por meio desses desafios as pessoas aprendem e se desenvolvem profissionalmente, levando tal experiência para toda sua vida. Na medida em que 20\% dos participantes do Grupo Tático responderam "não" à primeira pergunta, percebe-se um alto grau de exigência dos trabalhadores com maior poder de atuação na organização quanto ao que identificam como aquilo que profissionalmente sabem fazer de melhor. A unanimidade presente no Grupo Operacional é um dado que favorece a interpretação de todas as demais respostas.

A segunda pergunta, "você recebe reconhecimento pelas suas atividades no trabalho?", procurou investigar o contato dos participantes com reforço social. Picado (2009, p.15) especifica o que seriam reforços sociais: "o elogio (exemplo: fizeste um bom trabalho), o sorriso, a atenção (exemplo: estás, de fato, a melhorar significativamente)". 
Gráfico 3. Reforço social
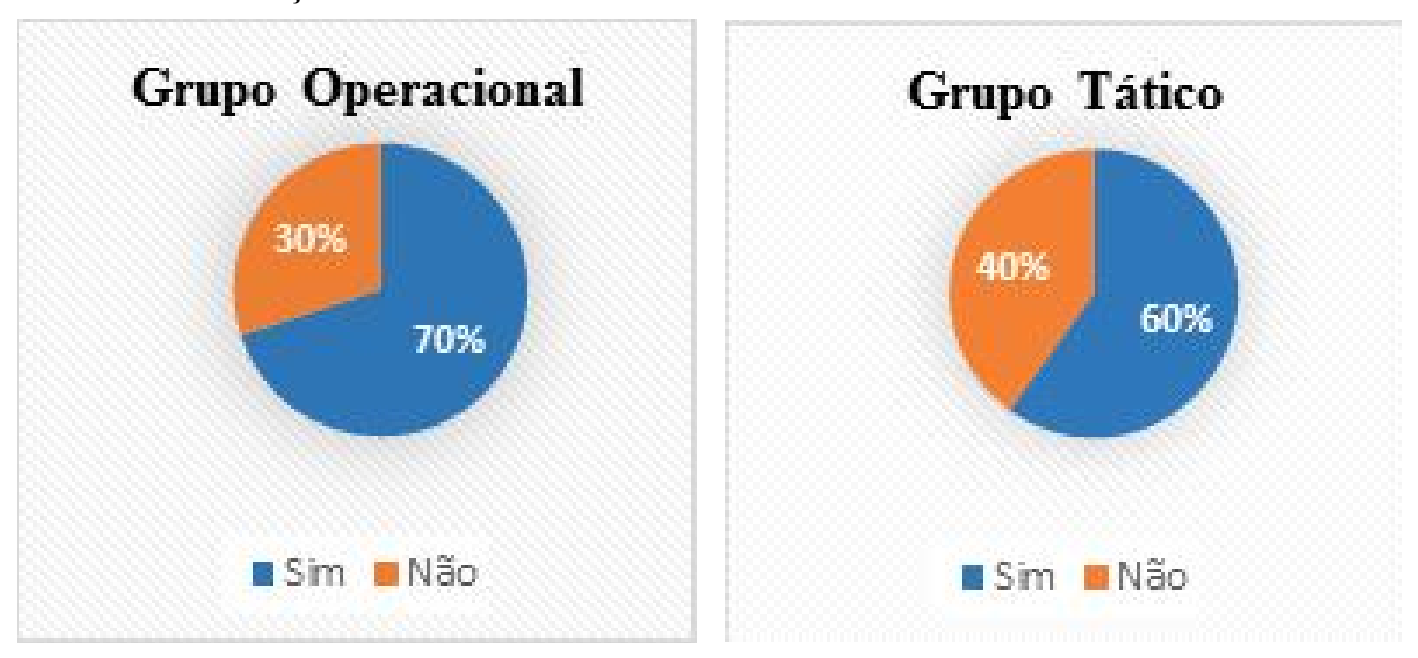

Fonte: Elaboração própria

Verifica-se a proximidade de respostas nos dois grupos acerca do contato com reforçador social referente ao reconhecimento de suas práticas profissionais, sendo este um critério relevante para a manutenção do comportamento de permanecer em uma organização. $70 \%$ de respostas positivas no Grupo Operacional e 60\%, no Grupo Tático são resultados praticamente equivalentes, mas vale destacar que, no caso deste último grupo, as respostas positivas e negativas estão mais próximas. É possível que, no Grupo Tático, o reforço intrínseco, liberado pela realização das atividades (primeira pergunta), compense a frequência relativamente baixa de reforço social, o que pode ser considerado com maior clareza mediante as respostas às perguntas seguintes.

A terceira pergunta, "você considera sua remuneração adequada para sua função?", voltou-se a um reforçador extrínseco e generalizado, aquele que pode ser emparelhado com outros reforçadores primários ou naturais (por exemplo, alimento) nas mais variadas circunstâncias. Skinner (2003, p. 343) indica que "o dinheiro é um reforçador generalizado por excelência porque [...] pode ser permutado por reforçadores primários os mais variados".

Gráfico 4. Reforço generalizado

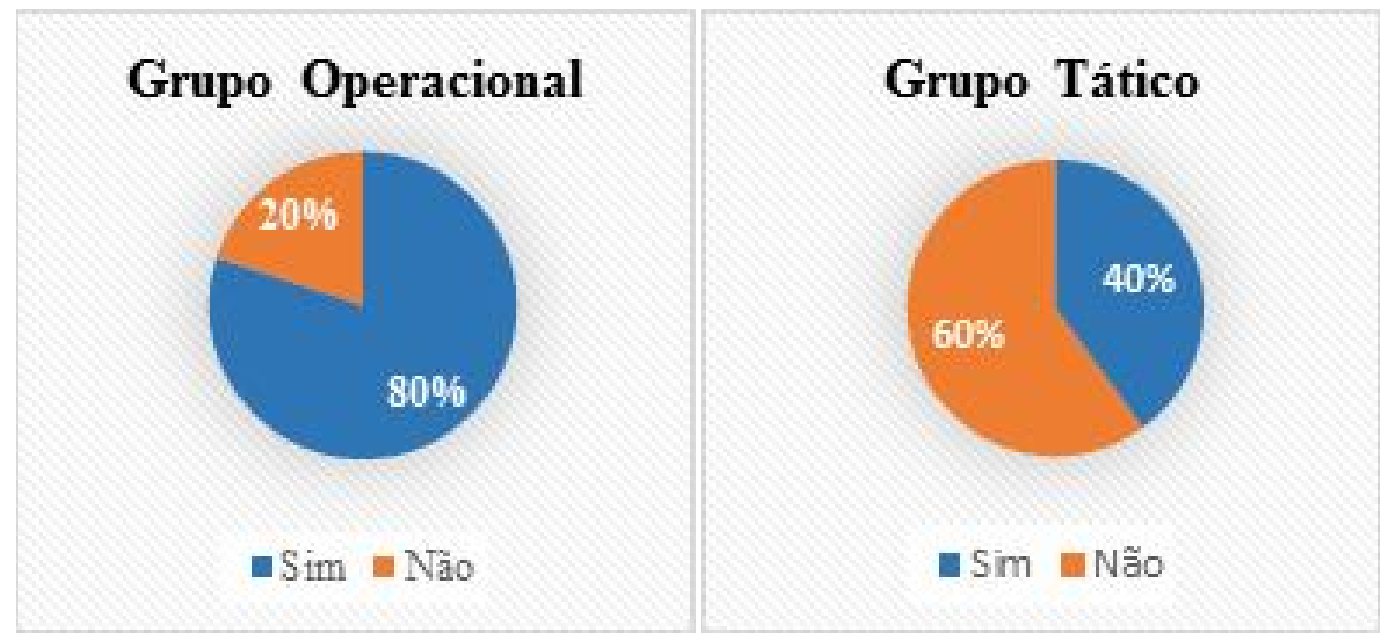

Fonte: Elaboração própria 
Verifica-se que o reforço referente à remuneração não é considerado como adequado pelos participantes do Grupo Tático (40\% de respostas afirmativas), resultado este bastante contrastante com o do Grupo Operacional (80\% de respostas afirmativas).

Permanece, assim, em aberto a questão mais ampla, referente aos reforçadores que mantêm os participantes do Grupo Tático em seus empregos. É possível, portanto, que o resultado referente aos grupos, em sua totalidade, não deixe claro o posicionamento de cada participante. Neste sentido, enquanto alguns consideram entrar em contato com reforço intrínseco, outros destacam o reforço social e outros, reforço generalizado, o que significa que os comportamentos individuais são assim explicados, mas, enquanto grupo, resultados positivos permanecem relativamente baixos.

A quarta pergunta, "você tem voz ativa na empresa?", remete à aquisição de função positivamente reforçadora por respostas de terceiros relacionadas a reconhecimento ou obediência, ou seja, pela possibilidade de autonomia ou mesmo pela adoção de papel de autoridade. Conforme Evans (1996, p. 16), uma "tendência social muito marcante é a autonomia. As pessoas querem se sentir independentes, autônomas; querem ter o controle de suas próprias vidas, distanciando-se do poder impessoal, que representa autoridade" de outros sobre ela.

Gráfico 5. Função reforçadora de autonomia e/ou autoridade

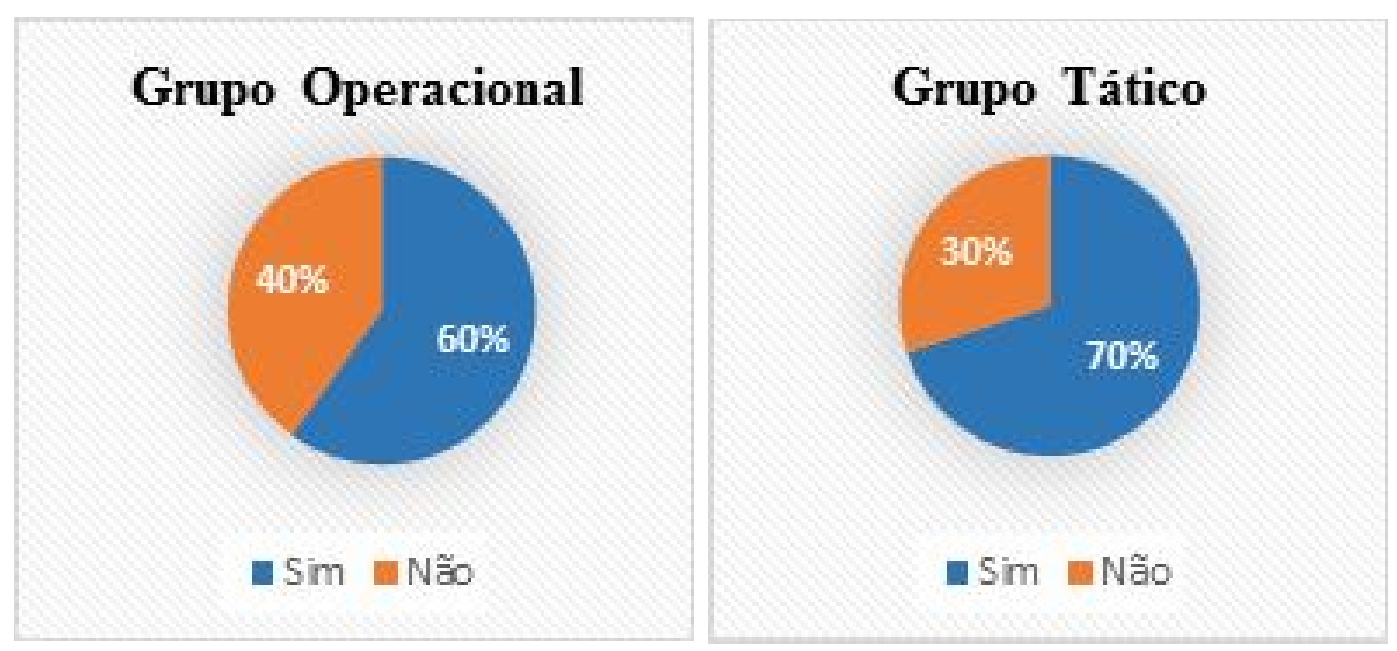

Fonte: Elaboração própria

Delegar atividades e fornecer autonomia para o trabalhador resolver situações por conta própria é uma forma de dar a ele desafios profissionais e poder de decisão, tornando suas atividades mais dinâmicas. Tal perspectiva reflete o conceito de empowerment, surgido na década de 1980 (FREIRE; SHOR, 1986), e desenvolvido em direção à abordagem de desenvolvimento participativo (CHAMBERS, 1994).

$70 \%$ dos participantes do Grupo Tático reconhecem o valor de ter voz ativa na empresa, assim como $60 \%$ daqueles do Grupo Operacional. É possível que os participantes do Grupo Operacional tenham relacionado "voz ativa na empresa" com a relativa liberdade que têm ao executarem as diferentes atividades relacionadas à função de venda. Verifica-se, assim, a importância da interpretação pessoal da realidade para que a função reforçadora ou punitiva possa ser relatada. $30 \%$ de respostas negativas no Grupo Tático fortalece tal hipótese na medida em que as funções atribuídas a tais participantes, ao menos teoricamente, são referentes à "voz ativa", ainda que não sejam assim 
percebidas. A interpretação individual das circunstâncias de trabalho, portanto, parece favorecer mais o Grupo Operacional do que o Grupo Tático.

A quinta pergunta, "você se sente realizado em seu trabalho?", remete a um efeito emocional do contato com contingências de reforçamento positivo. Realização profissional e produtividade estão estritamente relacionadas, e garantir a felicidade do trabalhador é também aumentar os resultados da organização. Conforme Amorim e Campos (2002, p. 7), "a possibilidade de estar com a mente saudável, ser reconhecido pelo trabalho que se realiza e gostar do que se faz são manifestações que colaboram com a postura gerencial adotada na busca da felicidade dos sujeitos". Sato e Schmidt (2004, p. 366) ampliam tal perspectiva: "trabalhar é condição sine qua non para viver. Não o é, apenas, para viver materialmente, mas para que alguém seja socialmente confiável. Ser confiável é ter o testemunho de outro que lhe atribui existência social".

Gráfico 6. Efeito emocional de reforçamento positivo

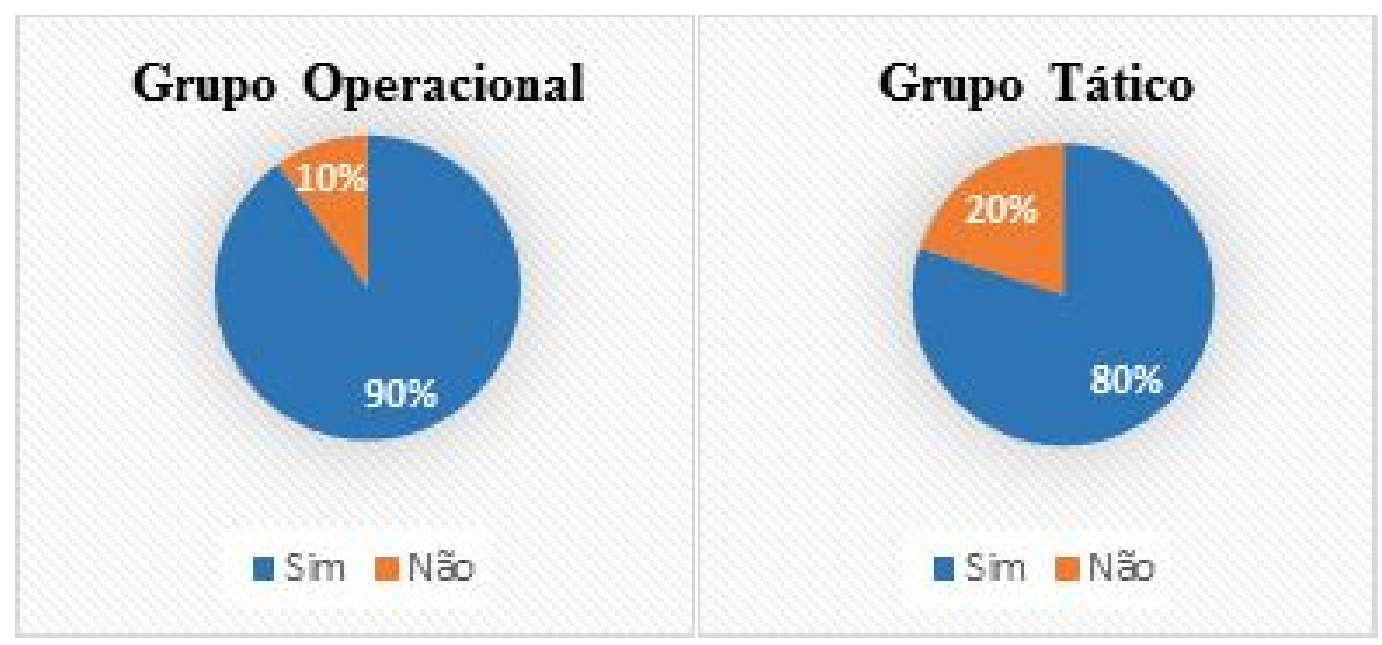

Fonte: Elaboração própria

Observa-se que a maioria dos trabalhadores entrevistados relatou se sentir realizada em seu cargo de trabalho, seja ele operacional (90\%) ou tático (80\%). Percebe-se o impacto de reforçadores presentes na realização das tarefas de ambos os grupos de participantes sobre aspectos emocionais. Segundo Guimarães (2005, p. 22), a realização profissional está relacionada ao bem-estar, que é atingido para além do alcance de prazeres, sendo "fundamental que o indivíduo busque e sinta que o seu verdadeiro potencial está sendo utilizado".

É possível que o efeito emocional aqui enfocado esteja diretamente relacionado ao contato com reforço intrínseco investigado na primeira pergunta ("em seu trabalho você tem a oportunidade de fazer todos os dias aquilo que você sabe fazer de melhor?"), em que 100\% do Grupo Operacional e $80 \%$ do Grupo Tático responderam afirmativamente. De maneira geral, no entanto, tal efeito emocional deriva de todo e qualquer contato estabelecido com reforçamento positivo.

A sexta pergunta, "o seu trabalho o deixa entediado?", investiga o tédio, que pode ser compreendido como um efeito emocional esperado do contato com reforçamento positivo que se repete várias vezes e é, portanto, de fácil acesso, o que compromete seu efeito reforçador. Verificase, em tais casos, que a frequência da resposta permanece alta, mas o efeito de prazer se perde (SKINNER, 1987). 
Gráfico 7. Desgaste no efeito prazeroso de estímulos reforçadores
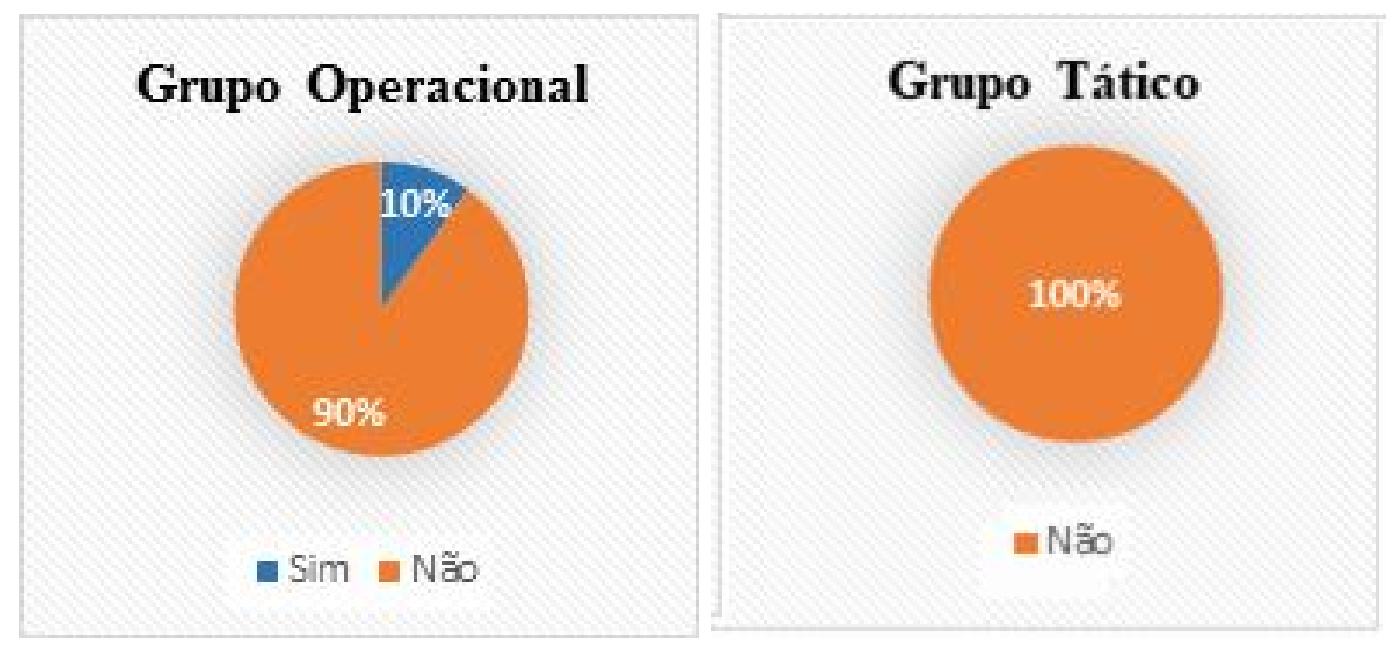

Fonte: Elaboração própria

90\% dos participantes do Grupo Operacional e 100\% daqueles do Grupo Tático responderam "não" a essa pergunta. A baixa frequência de sensação de tédio é tida como um fator relacionado com satisfação no emprego. Em todo o caso, indica que as atividades realizadas pelos participantes não são repetitivas por natureza ou que eles as tornam mais diversificadas ou mesmo que as percebem de modo tal que o efeito reforçador se mantém presente apesar de as atividades serem executadas cotidianamente. A unanimidade nas respostas do Grupo Tático pode ser acolhida com surpresa diante das anteriores, porém reflete particularidades teoricamente esperadas, dadas as características mais dinâmicas das atividades. Além disso, percebe-se que os participantes de tal grupo apresentam maior facilidade em reconhecer a ausência de emoções negativas à presença de emoções positivas.

A sétima pergunta, “o que o motiva a trabalhar?”, é voltada à percepção ampla de reforçadores no ambiente de trabalho. Segundo Ramos (1990), estudos sobre a motivação geram repercussões no mundo do trabalho, no sentido da possibilidade de sensibilizar a organização no processo de produção e bem-estar psicológico. Destaca-se que, além de a organização tentar disponibilizar aos trabalhadores a oportunidade de contato com reforçamento positivo, é importante que estes assim o percebam. Além disso, abre-se a possibilidade para a identificação de fontes de reforço que sejam extrínsecas ao ambiente de trabalho. 
Gráfico 8. Identificação de reforçadores

\section{Grupo Operacional}

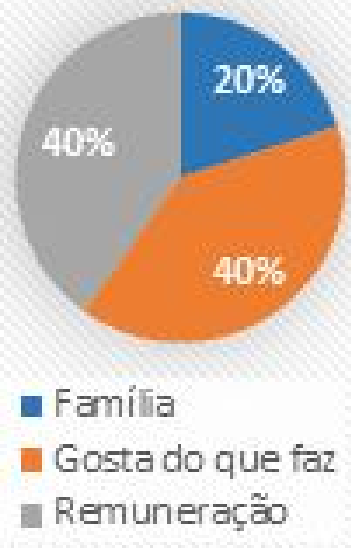

\section{Grupo Tático}

$10 \%$

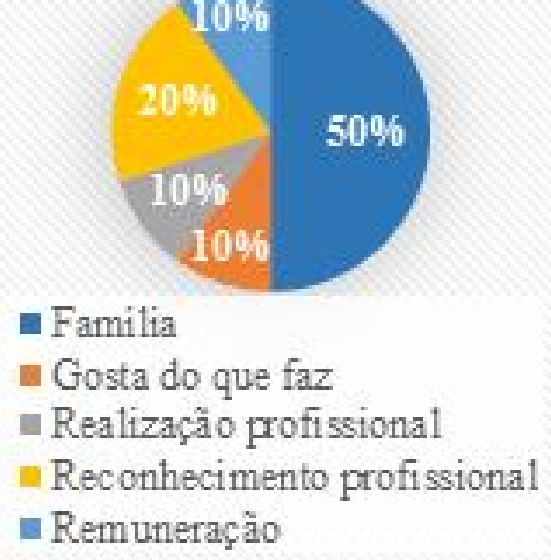

Fonte: Elaboração própria

O Grupo Operacional citou fatores como gostar do que faz (40\%), remuneração (40\%) e família, mais especificamente quanto ao sustento familiar (20\%), enquanto o Grupo Tático apontou principalmente a família, com a mesma ênfase no sustento (50\%), e o reconhecimento profissional (20\%). Gostar do que faz, realização profissional e remuneração foram fatores indicados, cada um, apenas por $10 \%$ dos participantes deste grupo.

Assim, 50\% dos participantes do Grupo Tático e 20\% daqueles do Grupo Operacional destacaram o sustento da família como motivador preponderante. Segundo Henriques, Carneiro e Magalhães (2006, p. 331), o sentimento de instabilidade e individualidade que a economia gera no ambiente de trabalho faz com que a família seja vista "como refúgio diante do mundo instável e incerto". Daí, portanto, a importância de investir no sustento ou participar da renda que viabiliza a sobrevivência dos membros da família.

Considerando-se que os fatores referentes à remuneração e ao sustento da família como equivalentes, $60 \%$ dos participantes de cada grupo indicaram, como fonte de motivação no trabalho, tais reforçadores extrínsecos e generalizados. Tal resultado, bastante significativo, é relativizado no Grupo Operacional, em que $40 \%$ dos participantes indicaram gostar das atividades que realizam. No Grupo Tático, pelo contrário, apenas $10 \%$ estão satisfeitos com as atividades desempenhadas no trabalho. No caso em que reforçadores extrínsecos e generalizados assumem o controle, como neste segundo grupo, vale considerar a possibilidade de que respostas variadas estejam sendo mantidas por reforçamento negativo. Neste sentido, trabalhar geraria prazer apenas no sentido de garantia de renda, sendo as atividades cotidianas realizadas justamente como forma de evitar a perda dessa renda. O pouco tempo de trabalho dos participantes do Grupo Tático (no máximo, dois anos) pode ser um indicativo de alta rotatividade e, em todo o caso, percebe-se que o fato de as atividades de tais cargos serem teoricamente mais reforçadoras não garante que, na prática, elas o sejam.

A nona pergunta, "você ficaria mais três anos no seu atual cargo?", procurou avaliar a percepção sobre a permanência no ambiente de trabalho, refletindo efeitos de reforçamento que se estenderiam no tempo. 
Gráfico 9. Efeitos de longo prazo do reforçamento

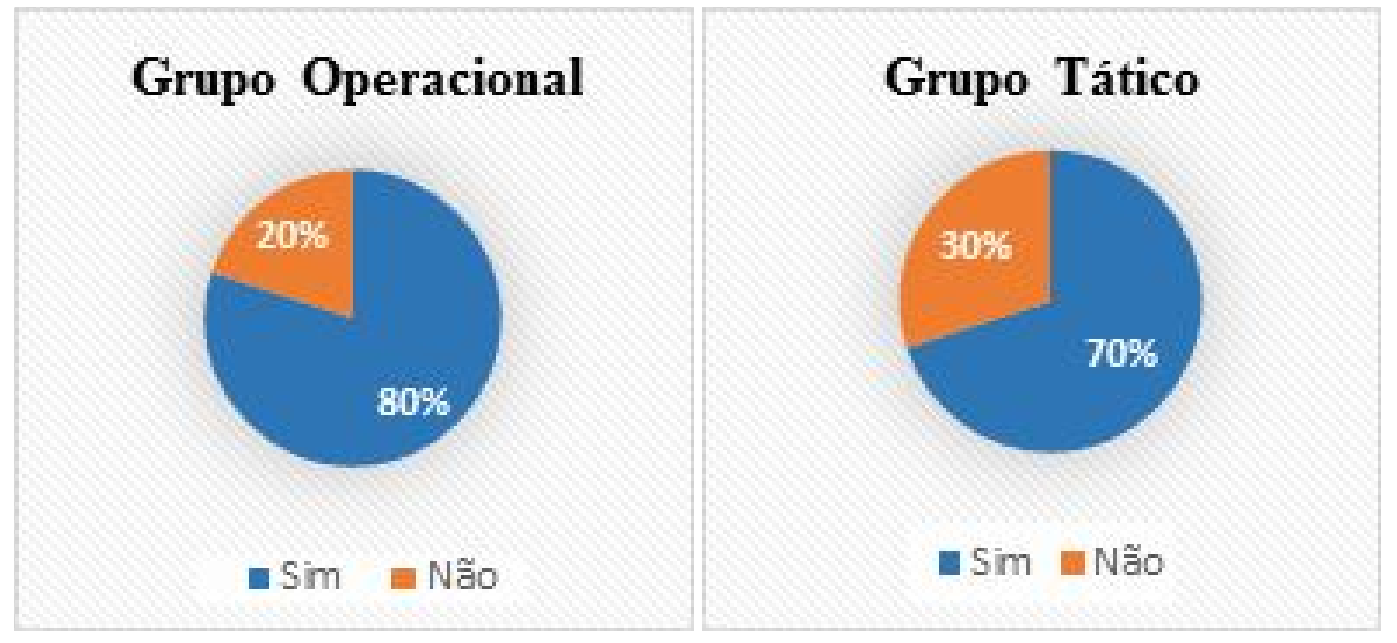

Fonte: Elaboração própria

A décima pergunta, "por que você ficaria mais três anos no cargo atual?", foi acrescentada enquanto tentativa de fechar uma conclusão acerca dos diferentes fatores isolados que resultaram de todas as perguntas.

Gráfico 10. Futuro profissional

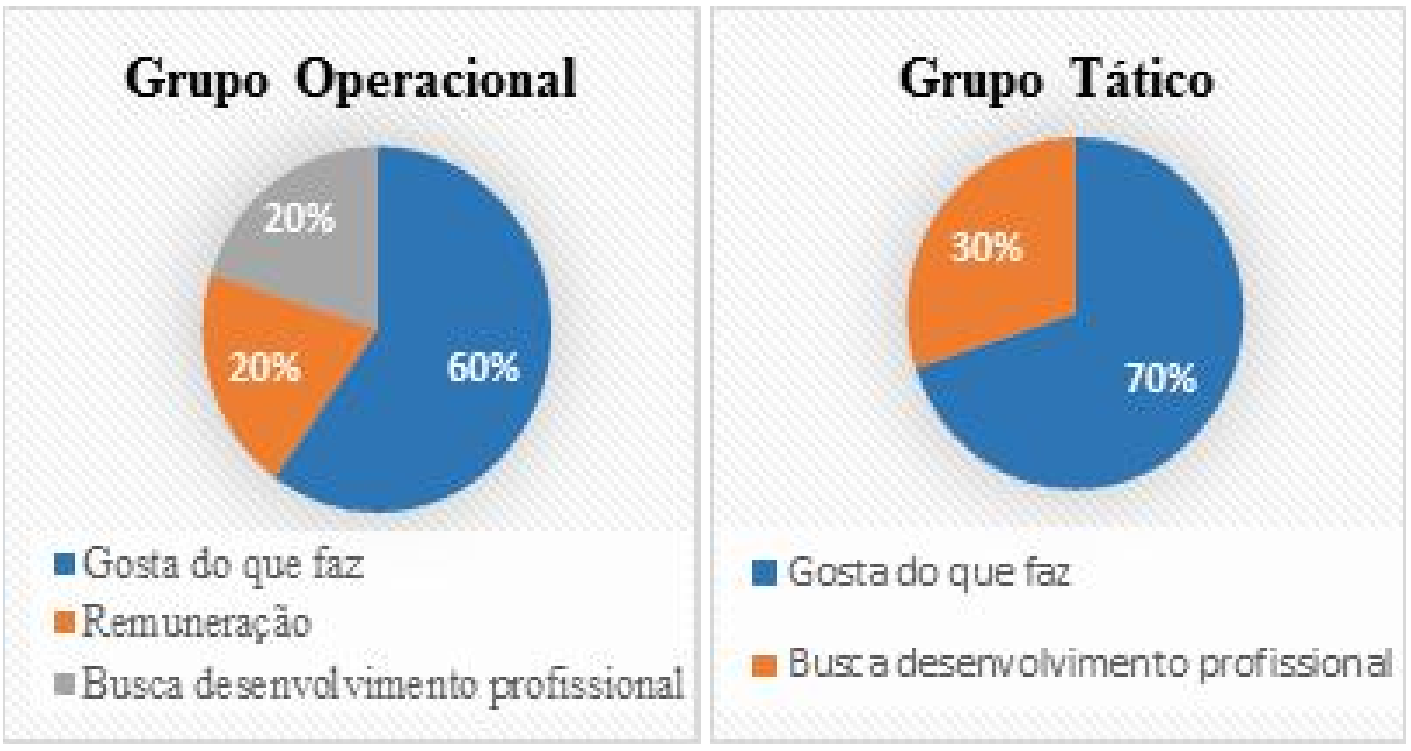

Fonte: Elaboração própria

No Grupo Operacional, 80\% dos participantes continuariam mais três anos no atual cargo. Destes, $20 \%$ justificam a resposta por causa da remuneração (reforçador extrínseco e generalizado) e $60 \%$ por gostarem do que fazem (reforçador intrínseco). Os $20 \%$ dos entrevistados que responderam que não ficariam mais três anos no atual cargo relataram, como motivo, a busca de evolução profissional. No Grupo Tático, $70 \%$ dos participantes continuariam mais três anos no atual cargo, e todos por gostarem das atividades que desempenham. Os 30\% que não ficariam no atual cargo por mais três anos também relataram como motivo a busca da evolução profissional.

Neste sentido, os participantes de ambos os grupos que responderam negativamente não relacionaram o desejo de desligamento da organização por fatores diretamente relacionados a ela, 
mas por buscarem evolução em suas carreiras. Seja como for, a grande maioria relatou que pretende permanecer por mais três anos em seus respectivos cargos.

O motivo da permanência no cargo, principalmente quanto ao Grupo Tático, "gostar do que faz" (70\%), sofreu uma enorme variação em relação à sétima pergunta (10\%), sendo que o número de tais respostas também aumentou em $20 \%$ no outro grupo. Para maior compreensão de tal variação, destaca-se, inicialmente, que, entre as duas perguntas havia uma outra, referente ao tempo de permanência no cargo atual, a qual passou a integrar o item de descrição dos participantes (Gráfico 1). É necessário, portanto, considerar o efeito favorecedor de reflexão da própria entrevista, de maneira que o efeito prazeroso do trabalho esteve menos perceptível quando, inicialmente, os participantes pensaram acerca do presente, ou seja, de suas atividades cotidianas. Em seguida, na pergunta que se refere ao futuro, eles demonstraram perceber mais claramente que gostam do que fazem e, assim, demonstraram a complexidade de estabelecimento de contato com a própria subjetividade.

\section{CONCLUSÃO}

Neste estudo, o estabelecimento de pontes entre contexto, ação, pensamento e emoção, nos moldes previstos pela Análise do Comportamento, destacou a importância da presença de contato com reforçamento positivo na situação de trabalho em dois cargos substancialmente diferentes. Temse em conta que o simples fato de se estar trabalhando já pode ser visto como conjunto de atitudes que gera contato com reforço, pois, além da remuneração que garante, o trabalho faz parte do status do ser humano na sociedade, em nossa cultura. No entanto, a comparação da percepção de reforçadores entre os grupos evidenciou a complexidade da análise que deriva das múltiplas variáveis referentes à subjetividade humana e envolvidas no autoconhecimento e na avaliação de relações sociais.

Diferenças entre reforçadores contingentes ou intrínsecos e não contingentes ou extrínsecos à situação de trabalho foram encontradas de duas formas peculiares: em referência a trabalhar, de uma maneira geral (pergunta 8), quando, nos dois grupos, a maioria das respostas apontou a importância de fatores externos à situação de trabalho (família e remuneração), e, por outro lado, em referência a permanecer mais três anos na empresa (pergunta10), quando a maioria das respostas apontou fatores intrínsecos ao trabalho (os participantes disseram que gostam do que fazem). As explicações "trabalho porque preciso" (indicando presença de reforçamento negativo) e "permaneço no emprego porque gosto do que faço" (indicando presença de reforçamento positivo) parecem ser contraditórias. No entanto, pode ser mais fácil justificar um ato atual pela necessidade que se tem de executá-lo do que admitir querer permanecer em um lugar que não se ocupa com prazer. Uma outra variável a ser considerada, conforme descrito anteriormente, é a possibilidade de a sequência de perguntas ter ajudado os participantes a entrar em contato com suas motivações mais profundas.

Os reforçadores disponíveis a cada grupo foram considerados como adequados e suficientes pela maioria dos participantes dos dois grupos. Percebe-se, portanto, a possibilidade de uma adequação de tais trabalhadores a seus respectivos cargos. Curiosamente, as respostas às perguntas 2, 4, 6 e 10 foram mais positivas no Grupo Operacional. Verificou-se, assim, a concretização de um princípio básico da Análise do Comportamento, segundo o qual o valor reforçador dos estímulos depende de fatores múltiplos, muitas vezes obscuros para quem observa as relações e mesmo para o próprio indivíduo implicado no processo. 
Em todo o caso, outros estudos poderiam ser realizados de modo a esclarecer melhor os resultados aqui descritos. Uma variável que precisa ser analisada é o histórico de empregos dos participantes. É provável haver diferenças na experiência subjetiva de estar trabalhando quando se está no primeiro emprego ou quando se teve um emprego considerado menos adequado ou mesmo quando se passou um longo período desempregado. Considera-se a possibilidade de que tais fatores possam impactar a percepção atual dos participantes acerca do emprego que têm de maneira positiva, por mais que na organização haja poucos reforçadores disponíveis.

Outra variável relacionada a esta primeira é a escolaridade dos participantes e os valores a ela atribuídos, gerando expectativas positivas ou negativas. Um vendedor pode compreender seu cargo como sendo muito gratificante, ao contrário do que avalia um supervisor acerca de sua posição na organização, dependendo do que cada um desses indivíduos idealizou para o seu futuro e do quanto investiram para a realização de seus planos de trabalho.

Os resultados advindos deste estudo destacam pontos importantes acerca da dinâmica complexa de reforçadores que tornam semelhantes as experiências de trabalho por pessoas que ocupam cargos substancialmente diferentes. $\mathrm{O}$ contato com estímulos reforçadores intrínsecos e extrínsecos acarreta efeitos que se distanciam na medida em que o trabalho passa a ser vivenciado enquanto fonte de prazer ou, por outro lado, como forma de conseguir dinheiro (reforçador generalizado) ou reconhecimento (reforçador social). Em linhas gerais, as entrevistas analisadas neste estudo apontam para a possibilidade de, no equilíbrio entre diferentes tipos de reforçadores, repousar a realização profissional independentemente do cargo assumido.

\section{REFERÊNCIAS}

AMORIM, M. V.; CAMPOS, A. C. C. F. A felicidade no trabalho: estudo sobre sua revelação e a articulação com a produtividade. Encontro nacional de engenharia de produção, 2002.

BADURA, B.; DUCKI, A.; SCHRÖDER, H.; KLOSE, J.; MEYER, M. (Eds.). Fehlzeiten-Report 2018: Sinn erleben - Arbeit und Gesundheit. New York: Springer, 2018.

BAJOIT, G.; FRANSSEN. O trabalho, busca de sentido. Tradução: Denice Barbara Catani. Rapport de recherche au Fonds de la Recherche Fondamentale Collective. n.8, p. 76 - 95, 1997.

BORGES, M. A. G. A compreensão da sociedade da informação. Ci. Inf., Brasília, v. 29, n. 3, p. 25-32, set./dez. 2000.

CAMPOS, A. S. A. Consequências arbitrárias: Análise de diferentes magnitudes em cadeias de respostas públicas e privadas. 2009. 79f. Dissertação (Mestrado de psicologia) - curso de pósgraduação em psicologia. Universidade católica de Goiás. Goiânia.

CASTELlS, M. A sociedade em rede. A era da informação: Economia, Sociedade e Cultura. V. 1. Lisboa: Fundação Calouste Gulbenkian, 2002.

CATANIA, A. C. Learning. Englewood Cliffs: Prentice-Hall, 1998. 
CHAMBERS, R. Participatory rural appraisal (PRA): Analysis of experience. World Development, v. 22, n. 9, p. 1253-1268, 1994.

DARWICH, R. A.; TOURINHO, E. Z. Respostas emocionais à luz do modo causal de seleção por consequências. Revista Brasileira de Terapia comportamental e cognitiva, v. 8, n. 1, p 107- 118, 2005.

EVANS, P. Carreira, sucesso e qualidade de vida. Revista de administração de empresas, v. 36, n.3, p. 14-22, 1996.

FLEURY, M. T. L.; FLEURY, A. Construindo o Conceito de Competência. RAC, Edição Especial, p. 183-196, 2001.

FREIRE, P.; SHOR, I. Medo e ousadia: o cotidiano do professor. Rio de Janeiro: Paz e Terra, 1986.

FREITAS, H.; KLADIS C. M. O processo decisório: modelos e dificuldades. Rio de Janeiro.

Revista Decidir, v.2, n.8, p. 30-34, 1995.

GUIMARÃES, F. A. L. Realização profissional, prazer e sofrimento no trabalho e valores: um estudo com profissionais de nível superior. 2005. 147f. Dissertação (Mestrado de Psicologia) Curso de Pós-Graduação em Psicologia. Universidade Federal de Uberlândia. Uberlândia

HENRIQUES, C. R.; CARNEIRO, T. F.; MAGALHÃES, A. S. Trabalho e família: o prolongamento da convivência familiar em questão. Paidéia, v.16, n. 35, p. 327-336, 2006.

MOREIRA, M. B.; MEDEIROS, C. A. Princípios básicos de análise do comportamento. Porto Alegre: Artmed, 2007.

PICADO, L. A indisciplina em sala de aula. O portal dos psicólogos, 2009.

PICOLLI, I. R. A.; CASAGRANDE, J. L. Qualidade de vida no trabalho: uma análise bibliométrica em periódicos brasileiro entre 2005 e 2015. Revista FOCO, v.10, n. 3, p.172-190, 2017

RADOS, G. J. V.; INOMATA, D. O.; TRZECIAK, D. S.; MANHÃES, M. C. Serviço de informação como fator de vantagem competitiva nas organizações. Biblios (Peru), n. 65, p. 15-28, 2016.

RAMOS, J. P. Motivação no trabalho: abordagens teóricas. Psicousp, v.1, n.1, p. 127-140. São Paulo, 1990.

SATO, L.; SCHMIDT, M. L. S. Psicologia do trabalho e psicologia clínica: um ensaio de articulação focalizando o desemprego. Estudo de psicologia, v. 9, n. 2, p. 365-271, 2004.

SIDMAN, M. Coercion and its fallout. Massachusetts: Authors Cooperative, 1989. 
SKINNER, B. F. Ciência e comportamento humano. 11º ed. São Paulo: Martins Fontes, 2003.

SKINNER, B. F. What is wrong with daily life in the western world? American Psychological Association, v. 41, n. 5, p. 568-574, 1987.

ZANELLI, J. C. O psicólogo nas organizações de trabalho. Porto Alegre: Artmed, 2004.

i Este estudo foi aprovado pelo Comitê de Ética em Pesquisa da Universidade da Amazônia (parecer no 029571/2017 e CCAE: 66529017.5.0000.5173). 